\section{"Valuable data" claim}

\section{Washington}

Controversy over the fate of the seven remaining "Silver Spring" monkeys looks set to intensify following claims that an experiment on one of the monkeys has yielded surprising and important results. Animal rights activists have long argued that nothing useful could be learnt from research on the severely disabled monkeys and that they should be transferred to an animal sanctuary. But the group of researchers who carried out the experiment last month say their data are very valuable and mean that the animals have not suffered prolonged disability to no good purpose.

The group of crab-eating macaque monkeys have been at the centre of a battle between animal rights activists and the National Institutes of Health (NIH) since 1981 when research being conducted by Edward Taub at the Silver-Spring based Institute for Behavioural Research was halted. Taub's experimental monkeys had been deafferented, so that they had lost sensation in one or both forearms, as part of an experiment to assess the effect of training on rehabilitation.

This year, on 14 January, a last-minute court decision (see Nature 343, 297; 25 January 1990) finally allowed a group of researchers from the National Institutes of Mental Health and several universities to carry out an experiment on one of the monkeys, named Billy, that had become very sick.

The researchers stress that the experiment was designed in accordance with an agreement reached between the Secretary of the Department of Health and Human Services and members of Congress that the animals would not be used for invasive procedures from which they would be allowed to recover. Euthanasia of Billy had already been recommended by veterinarians as his condition deteriorated. Experiments were conducted under anaesthesia and Billy was then allowed to die.

Preliminary accounts of the experiment given by Timothy Pons of the National Institutes of Mental Health in Bethesda, Maryland, reveal that an unprecedented degree of reorganization of Billy's sensory cortex had occurred. An 8-10-millimetre wide area of cortex that would normally receive input from the hand was found to have completely filled in with input from the face.

The great degree of change in cortical organization is presumably a result of the very long period for which Billy was without sensory input from his forearms. Ironically, Billy had been kept alive with his disability for a decade only as a result of the political and legal problems that mired NIH as it struggled with animal rights activists. Under the original plan for the experiment, Billy would have been euthanatized many years ago and the experiment would not have been possible.

The researchers disagree utterly with claims by animal rights organizations that their experiment was concocted to help justify NIH's long-standing refusal to hand over the monkeys to an animal sanctuary. They point out that they approached NIH at their own initiative in 1987. They say that they had realized that the new knowledge then emerging about cortical reorganization made the animals particularly valuable in a way that was largely unanticipated when Taub planned his own experiment eight years earlier.

Opponents of the experimental use of the monkeys remain unconvinced. Neal Barnard, president of the Physicians Committee for Responsible Medicine (PCRM) which last month unsuccessfully called for an enquiry into the experiment by the DHSS Office of Scientific Integrity Review, says the result is predictable and of no great significance.

Barnard says that during earlier court battles he told a judge that "NIH desperately needs data and although we all know that brain reorganization has long been known to occur they will show 'wow we've got brain reorganization over one square centimetre isn't that phenomenally amazing' ... The only people who are enthusiastic about the results are other people doing these brain-mapping studies," says Barnard, "Science has become secondary to public relations and politics".

Not so argues Pons. "Anyone who does these kinds of mapping studies and would know what to expect would be surprised, if not shocked, by the result. In fact, there has never been a report of complete reorganization, to my knowledge, after deafferentation, especially in an adult. It has never been predicted."

David Hubel, Nobel laureate and Professor of Neurobiology at Harvard Medical School, describes the result as "clearly important". Earlier work, he notes, has shown a smaller degree of cortical reorganization which was rather close to the resolution of the method. Here, several hundred recordings indicate an $8 \mathrm{~mm}$ square piece of cortex has filled in with input from the monkey's face. $\mathrm{He}$ adds that it would have been "almost criminal to let the monkey simply die, when you could conduct an experiment without the least suffering on the part of the animal."

Alex Pacheco of PETA says he wants to see the work in print and hear the opinions of independent neuroscientists before he makes a judgement. "NIH has too much of a vested interest", he says, "they have no choice but to say they are learning great things".

\section{UN fragments over treaty}

\section{Washington}

IN protest at the slow pace of United Nations (UN) global warming negotiations, a splinter group of nine countries last week said they would soon begin work on their own treaty to limit greenhouse gases, with the hope that the United States and other nations will eventually join in.

The group hopes to begin treaty negotiations in late summer, after the report from last week's UN climate change meeting in Washington is completed. "We don't need 'final scientific proof'. We think there is already enough evidence of a global warming", says Heintz Schreiber, head of the Austrian delegation to the UN Intergovernmental Panel on Climate Change (IPCC).

The Austria-led initiative already has the support of Denmark, France, West Germany, Italy, the Netherlands, Norway, Sweden and Switzerland. Further participants are expected, but the sponsors acknowledge that they do not know exactly how many, or which, countries will be necessary to achieve the "critical mass" that could result in worldwide endorsement. "the groups hopes to have a treaty before the end of 1991 .

In a statement, the group said that it is "concerned that any delay in action may endanger the future of further generations of mankind". It hopes that, with a working treaty in place, major industrialized nations such as the United States and Japan - as well as many developing countries - will be forced by public opinion to agree to greenhouse gas limits.

Although the group has set no specific targets for emissions, they intend to use the developing consensus that emerged from last week's IPCC meeting as a foundation. The IPCC scientific panel is preparing a draft report that is expected to predict temperature rises of between 1.5 and $4.5^{\circ} \mathrm{C}$ by 2030 and a sea level rise of $20-30 \mathrm{~cm}$, given a doubling of $\mathrm{CO}$, levels.

A report released by Greenpeace at the meeting concludes that, with substantial emission-control measures, global temperatures could eventually stabilize at between $1.1^{\circ} \mathrm{C}$ and $3.1^{\circ} \mathrm{C}$ above the preindustrial level. Among the controls that would be necessary are halting chlorofluorocarbon production by 1995 , reducing energy-related $\mathrm{CO}_{2}$ to 30 per cent of the present value by 2020 , and extensive reforestation, the 80-page peer-reviewed report finds. The report's author, Mick Kelly of the Climate Research Unit of the University of East Anglia, says such restrictions "would require a major shift in energy policy, but [are] not beyond the bounds of possibility".

G. Christopher Anderson 